\title{
Influence of the fly ash and the prior freezing and thawing on the sulphate resistance of cement mortars
}

\author{
Julia Marczewska* \\ Department of Civil Engineering and Architecture, Kielce University of Technology, al.1000-lecia PP \\ 7, 25-314 Kielce, Poland
}

\begin{abstract}
The use of fly ash for the production of cement is a typical example of the utilization of by-products (waste) from various fields of production in construction, a significant reduction of $\mathrm{CO}_{2}$ emissions and reduction of energy consumption. However, in order to be able to determine the suitability of this additive in construction, it is necessary to examine the durability of cement composites with fly ash in various, often complicated, destructive environments. There are known publications regarding the durability of concretes with fly ash in individual environments. However, in natural conditions, several destructive environments are common at the same time. The article presents an attempt to reproduce natural conditions. This paper presents the results of sulphate expansion tests of air-entrained (AE) and non-air-entrained (nAE) Portland and fly ash cement mortars subjected to prior freezing and thawing. Despite significant strains experienced during freeze-thaw cycles, unlike the non-air-entrained Portland cement mortars, the non-air-entrained mortars made of fly ash cement did not exhibit any significant expansion when exposed to $\mathrm{Na}_{2} \mathrm{SO}_{4}$. For 17 months no expansion was found in the air-entrained mortars made of either of the cement types when immersed in $\mathrm{Na}_{2} \mathrm{SO}_{4}$ solution after freezethaw cycles. The results of the SEM and EDS analyses showed that gypsum and ettringite were the sulphate attack products in all the mortars. The highest amounts of ettringite were found in air voids.
\end{abstract}

\section{Introduction}

Bearing in mind the climatic conditions in Poland and the scale of use of multicomponent cements, it seems relevant to investigate the interaction of frost damage and sulphate attack on the durability of air-entrained and non-air entrained cement composites from various cements. The durability of cementitious composites is defined as the degree of resistance to cyclic freeze-thawing, penetration, carbonation, stresses, and the action of chemical agents, for example, sulphate attack. The properties of cement-based composites are usually examined during the effects of a single mechanism of durability deterioration. However, in existing constructions, cement-based composites are often exposed to structural damage due

\footnotetext{
* Corresponding author: jmarczewska@tu.kielce.pl
} 
to many destructive processes (mechanical, physical, chemical) simultaneous or alternate occurrence, which can lead to acceleration of destruction. Despite extensive knowledge on the sulphate attack of concrete, there have been cases of premature failure of concrete structures exposed to the sulphate environment [1]. This happens because the classic sulphate attack tests there are no such factors as, for example, $\mathrm{pH}$ variation, wetting-drying cycles or freezing/thawing, which accompany the corrosion of concrete during exploitation $[1,2]$. Miao et al. [3] investigating the effect of interaction of sulphate attack and frost deterioration of concrete found that combined destruction by sodium sulphate solution and frost had both positive and negative effects. Cyclical freezing and thawing caused microcracks in the concrete structure, which facilitated the penetration of the sulphate solution into the deeper layers. However, the lower temperature slowed down the diffusion of sulphate ions, which led to the slowing of sulphate attack.

Durability of concrete structures is mainly related to the properties of the surface layer of concrete $[4,5]$. The main idea of using fly ash is to modify the cement to improve its properties and reduce the cost of concrete production as well as the use of by-products (waste) from various production fields. During the pozzolanic reaction the fly ash reacts with $\mathrm{Ca}(\mathrm{OH})_{2}$ formed from clinker [6]. The calcium hydroxide disappears and the low-calcium $\mathrm{C}$ $\mathrm{S}-\mathrm{H}$ and C-S-A-H phase is formed, which is the most resistant to sulphate attack [7, 8]. Cement composites with fly ash have increased resistance to aggressive factors [9], mainly due to the reduced content of large pores, and thus increased tightness, the ion exchange ability decreases which counteracts the progress of corrosion reactions [10]. Kurdowski [11], Mehta [12] and Skalny [1] are of the opinion that the physical effect of reducing porosity and capillary adsorption (permeability) as a result of the use of fly ash is much more important than their pozzolana activity. The use of fly ash in the production of concrete significantly changes the essential properties of cement paste, such as porosity, pore size distribution, absorption or the degree of water pore filling compared to concrete made of Portland cement. As a result, the frost resistance resulting from the mentioned characteristics will also be different. The reduction in the pore size leads to an increase in hydraulic resistance in the capillary pores [13]. Therefore, increasing the tightness of the concrete microstructure with the use of fly ash moves the crystallization of water into areas of lower porosity, which generates significantly higher pressures inside the material and thus reduces its frost resistance [14]. These undesirable effects can be limited by proper design of concrete, reduction of the w/c ratio, adequate air entrainment and careful care of the concrete [7].

The physical effects of sulphate attack and freeze-thaw cycle-related deterioration are similar in part, as in both cases swelling occurs, leading eventually to cracking.

\section{Experimental procedure}

\subsection{Aim and scope of the experiment}

The aim of this study was to investigate the effects of the fly ash on durability of cement mortars exposed to complex deterioration conditions. At 28 days of curing in water, part of the specimens were immersed in a $5 \% \mathrm{Na}_{2} \mathrm{SO}_{4}$ solution, whereas the other part were frozen and thawed for 40 cycles, after which they were immersed in the sodium sulphate solution. Freeze-thaw cycles were tested according to PN-88/B-06250 [15]. A Graf-Kaufman extensometer was used to systematically study linear strains in the mortars according to PNB-19707 [16]. All the tests were performed on $40 \times 40 \times 160 \mathrm{~mm}$ specimens. Scanning electron microscopy (SEM) with EDS analysis was used to explain changes in the microstructure and deterioration rate in the air-entrained and non-air-entrained cement mortars. 


\subsection{Materials}

The tests were carried out on mortars produced of industrial Portland cement CEM I $32.5 \mathrm{R}$ and fly ash cement CEM II/B-V 32,5R. The fly ash content declared by the cement plant was $27.7 \%$. The chemical and phase composition of Portland cement used for testing is shown in Table 1 . The w/c ratio was constant, equal to 0.50 . Tap water was used as batch water in accordance with PN-EN 206 [17]. Synthetic surfactants were used as an air entraining agent with a density of about $1.0 \mathrm{~g} / \mathrm{cm}^{3}$. In order to minimize the influence of uncontrolled factors, the mortars samples were prepared while maintaining identical manufacturing technology (identical order of added ingredients, mixing time and intensity, temperature and contact time of cement with water before measurements).

Table 1. Chemical and phase composition of Portland cement [\%]

\begin{tabular}{|c|c|c|c|c|c|c|c|c|c|}
\hline \multirow{2}{*}{ Cement } & \multicolumn{6}{|c|}{ Chemical composition } & \multirow[b]{2}{*}{$\mathrm{SO}_{3}$} & \multirow[b]{2}{*}{$\mathrm{Cl}^{-}$} & \multirow[b]{2}{*}{$\mathrm{Na}_{2} \mathrm{O}_{\mathrm{eq}}$} \\
\hline & $\mathrm{SiO}_{2}$ & $\mathrm{Al}_{2} \mathrm{O}_{3}$ & $\mathrm{Fe}_{2} \mathrm{O}_{3}$ & $\mathrm{CaO}$ & $\mathrm{CaO}_{\text {(wolne) }}$ & $\mathrm{MgO}$ & & & \\
\hline CEM I & 20.60 & 5.75 & 3.40 & 65.80 & 0.70 & 1.50 & 2.50 & 0.01 & 0.77 \\
\hline \multicolumn{9}{|c|}{ Phase composition } & $\mathrm{C}_{4} \mathrm{AF}$ \\
\hline CEM I & & & \multicolumn{2}{|c|}{63.20} & 8.20 & \multicolumn{2}{|c|}{6.30} & \multicolumn{2}{|r|}{9.90} \\
\hline
\end{tabular}

Half of the samples made from each cement were air entrained. The air content results in the fresh mortars are shown in Table 2. The air content was determined by the pressure method. The bulk density and consistency were additionally determined.

\section{Results}

The incorporation of additional air through the use of air entraining admixture reduced the bulk density of the both fresh mortars and changed their consistency, making them more fluid. After 28 days of curing, no significant differences in weight water absorption of the air entrained and non-air-entrained mortars were found (tab. 2). As it should be expected, the air entrained mortars had lower strength relative to that of the non-air-entrained mortars.

Table 2. Test results of fresh cement mortars and physical properties of cement mortars after 28 days of curing

\begin{tabular}{|lccccc|}
\hline \multicolumn{1}{|c}{ Properties of mortars } & \multicolumn{2}{c}{ CEM I } & \multicolumn{2}{c|}{ CEM II/B-V } \\
& $\mathrm{np}^{*}$ & $\mathrm{nnp}^{* *}$ & $\mathrm{np}$ & $\mathrm{nnp}$ \\
\cline { 2 - 6 } Air content in fresh mortar, \% & 9.0 & 3.0 & 9.0 & 2.8 \\
Consistency, spreading, mm & 223 & 180 & 212 & 168 \\
Bulk density, $\mathrm{kg} / \mathrm{m}^{3}$ & 2119 & 2259 & 2095 & 2212 \\
Compressive strength, $\mathrm{MPa}$ & 33.63 & 33.69 & 21.46 & 23.69 \\
Water absorption, \% & 9.1 & 8.92 & 8.82 & 9.64 \\
Difference in absorbability $\Delta \mathrm{n}_{\mathrm{w}}, \%$ & \multicolumn{2}{c}{0.18} & \multicolumn{3}{c}{0.82} \\
\hline
\end{tabular}

Remarks: *np - air-entrained, nnp - non-air-entrained.

After performing the basic tests of the cement mortars after 28 days curing in water, the samples were divided into two groups. The first group included the samples subjected to forty-six months sulphate attack after 40 freeze-thaw cycles were. For each test, the results presented were the average of the values obtained from six specimens under identical conditions. The non-air-entrained cement mortar with fly ash showed a fast progressing increase in linear strain as early as at 20 freeze-thaw cycles (fig. 1) and micro-cracks appeared on the specimen surfaces. These changes should be expected as the mortars produced from this cement have to be air-entrained in order to increase their resistance to freezing and 
thawing cycles $(18,19)$. These specimens, after the sulphate solution attack, presented the strains increase of only about $2 \%$. This low elongation of specimens resulted probably from micro-cracks formed, in which sulphate attack products could be crystallized, causing no stress. Further immersion in the $\mathrm{Na}_{2} \mathrm{SO}_{4}$ solution would probably cause their destruction.

The non-air-entrained Portland cement (OPC) mortar showed a low elongation (1.3\%o) after 40 freezing and thawing cycles. After placing these specimens in the sulphate solution, the strain started to increase at about five months and after 22 months the samples were destroyed. None of the air-entrained mortars showed deformation during initial freezing/thawing and the subsequent fifteen months in a solution of sodium sulphate. After this time, OPC mortar started to strain, initially to a small extent, and after 23 months suddenly. The specimens of the air-entrained mortar of cement CEM II/B-V did not show any deformations during the entire test period.

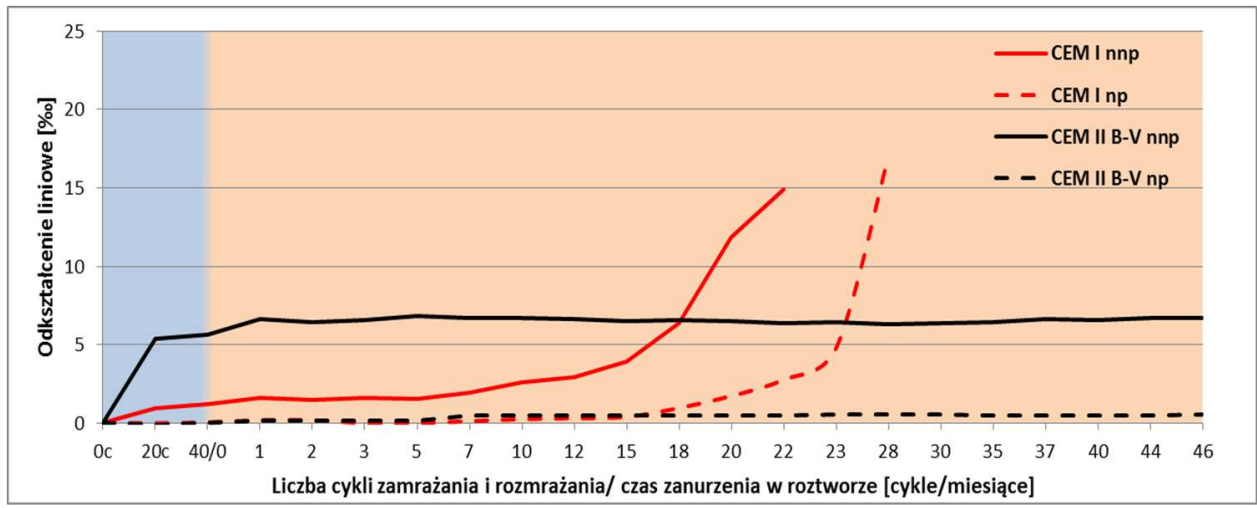

Fig. 1. Linear strains of AE (np) and nAE (nnp) mortars made from CEM I and CEM II/B-V subjected to 40 freeze-thaw cycles and then immersed in the $\mathrm{Na}_{2} \mathrm{SO}_{4}$ solution

The other mortars samples were only subjected to sulphate attack. After forty-six months immersed in sodium sulphate solution the non-air-entrained and air-entrained mortars with fly ash showed no linear deformation (fig. 2).

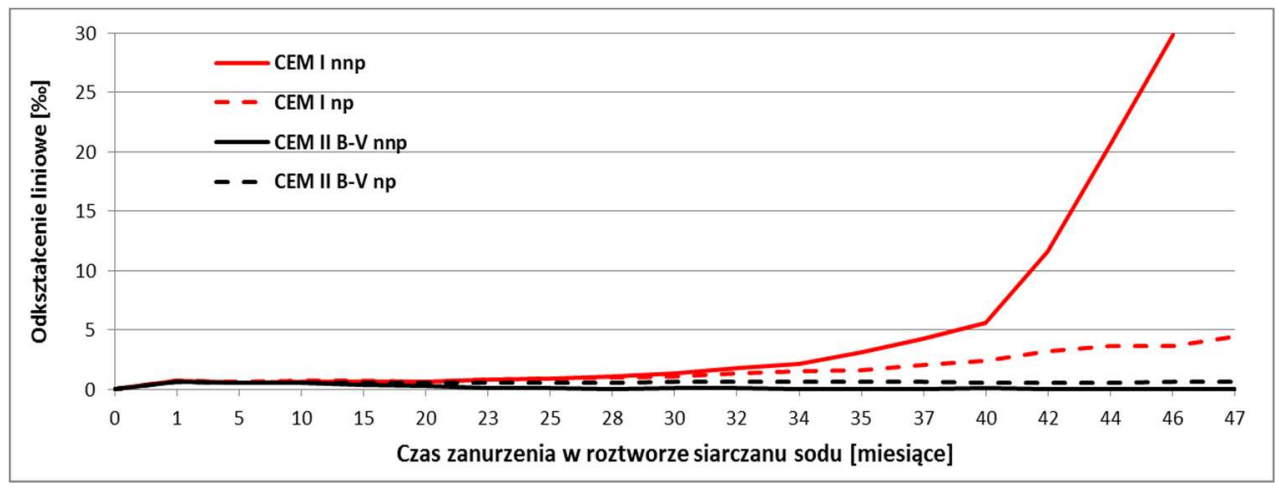

Fig. 2. Linear strains of AE (np) and nAE (nnp) mortars made from CEM I and CEM II/B-V immersed in the $\mathrm{Na}_{2} \mathrm{SO}_{4}$ solution

The air-entrained Portland cement mortars presented only slight deformation which beginning, after 32 months. The non-air-entrained Portland cement mortars have been destroyed, but much later than in the case of combined destruction.

After 40 months of sodium sulphate solution attack, in all tested mortars two phases: ettringite (fig. 3) and gypsum (fig. 4) as sulphate attack products were formed. The air voids 
of the air-entrained OPC mortars were partially filled with ettringite crystals (figs. 3a and $3 b)$. Figure $3 c$ shows the EDS of ettringite crystals aggregation at point A marked in figure 3a. Although often observed large and densely arranged ettringite crystals in the air voids, the air-entrained mortar showed no significant deformation. In non-air-entrained OPC mortars ettringite crystals were finer and less frequently observed.

To sum up the studies of Portland cement mortars, it has to be noted that deterioration affected the non-air-entrained mortars noticeably earlier both during plain sulphate attack and during sulphate attack preceded by frost damage. In these mortars ettringite was crystallizing in the compact C-S-H phase. As shown in figs. $3 \mathrm{a}$ and $3 \mathrm{c}$, in the specimens of air-entrained mortars ettringite was crystallizing mostly in the air-voids and thus cannot cause expansion.
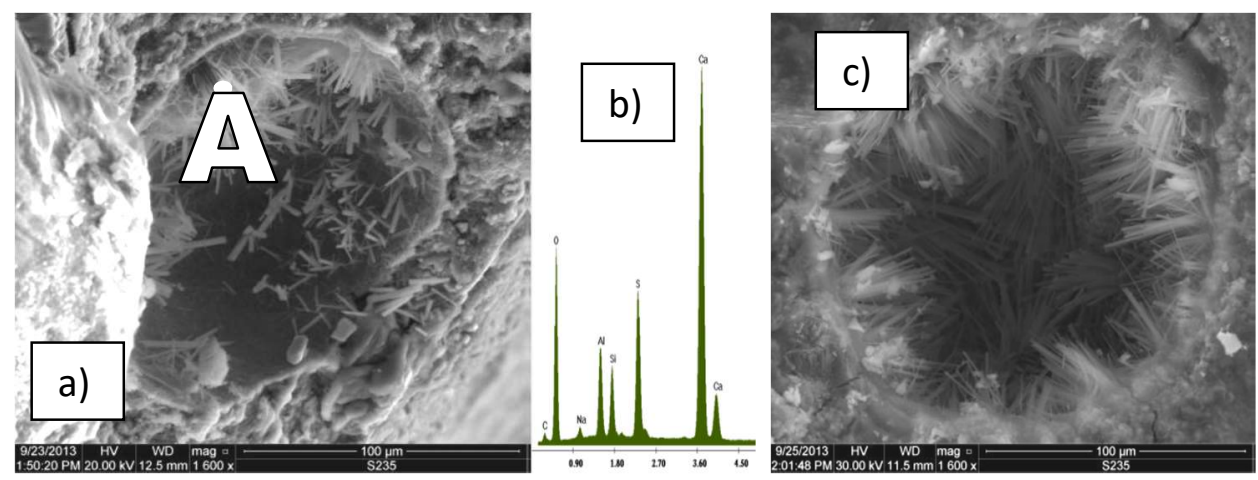

Fig. 3. Microstructure of air-entrained mortar of Portland cement immersed 40 months in $\mathrm{Na}_{2} \mathrm{SO}_{4}$; a), c) air voids; b) microanalysis at point A.

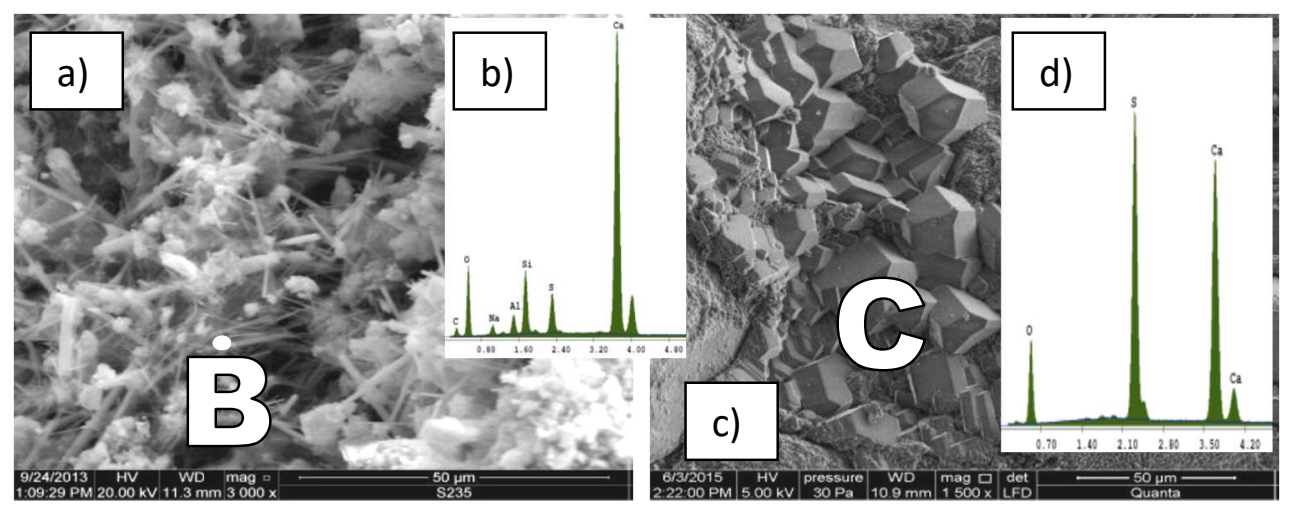

Fig. 4. Microstructure of non-air-entrained $\mathrm{OPC}$ mortar immersed 40 months in $\mathrm{Na}_{2} \mathrm{SO}_{4}$; a), c) ettringite; c) gypsum in microstructure C-S-H; microanalysis at b) point $\mathrm{B}$ and d) point $\mathrm{C}$

Also in the air-entrained fly ash cement mortar, ettringite was principally crystallizing in the air voids (figs. 5a, 5c) where there was crystallization of the free so does not cause expansion. The weak peaks for aluminum and sulfur shown in figure $5 \mathrm{~b}$, confirm a small amount of fine crystals of ettringite. The figure $5 \mathrm{c}$ shows the microstructure of fly ash cement mortar. She is more compact and, most likely, tighter than that of the OPC mortar. Analysis of the fly ash cement mortars microstructure indicates tight packing of hydration products, which hampers the penetration and migration of aggressive solutions. In the air-entrained mortar of fly ash cement after 40 freezing and thawing cycles and 20 months immersion in $\mathrm{Na}_{2} \mathrm{SO}_{4}$ solution no cracks appeared (fig. 8). And small crystals of sulphate corrosion products were observed only close to the surface of the samples. 
In the non-air-entrained mortar with fly ash immersed 40 months in $\mathrm{Na}_{2} \mathrm{SO}_{4}$ were detected only single and very fine ettringite crystals (fig. 6) in the cement matrix. In the non-airentrained mortar with fly ash numerous cracks (fig. 7) were observed, caused most probably by the cycles of freezing and thawing. Despite the cracks, the content of very small ettringite crystals, observed after nearly two years of sulphate attack, were low. Clusters of ettringite crystals could be observed only near the surface of the samples. Most often they grew inside the micro-cracks formed during the initial freezing/thawing, thus they did not cause expansion.

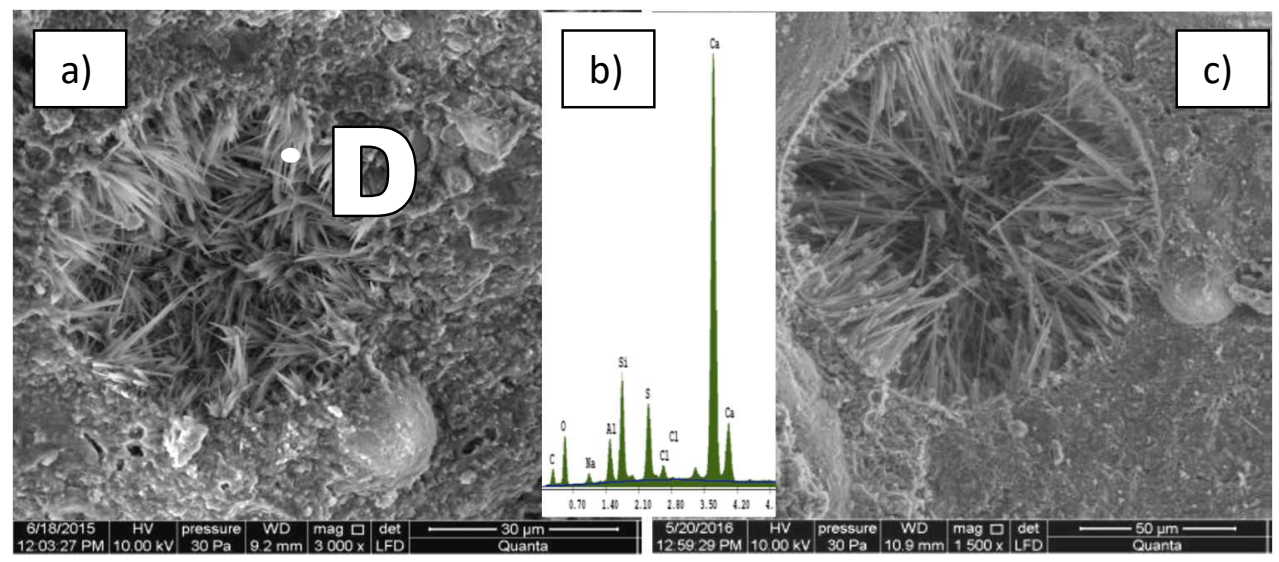

Fig. 5. Microstructure of air-entrained mortar with fly ash cement immersed 40 months in $\mathrm{Na}_{2} \mathrm{SO}_{4}$; a), c) air voids; b) microanalysis at point $D$.
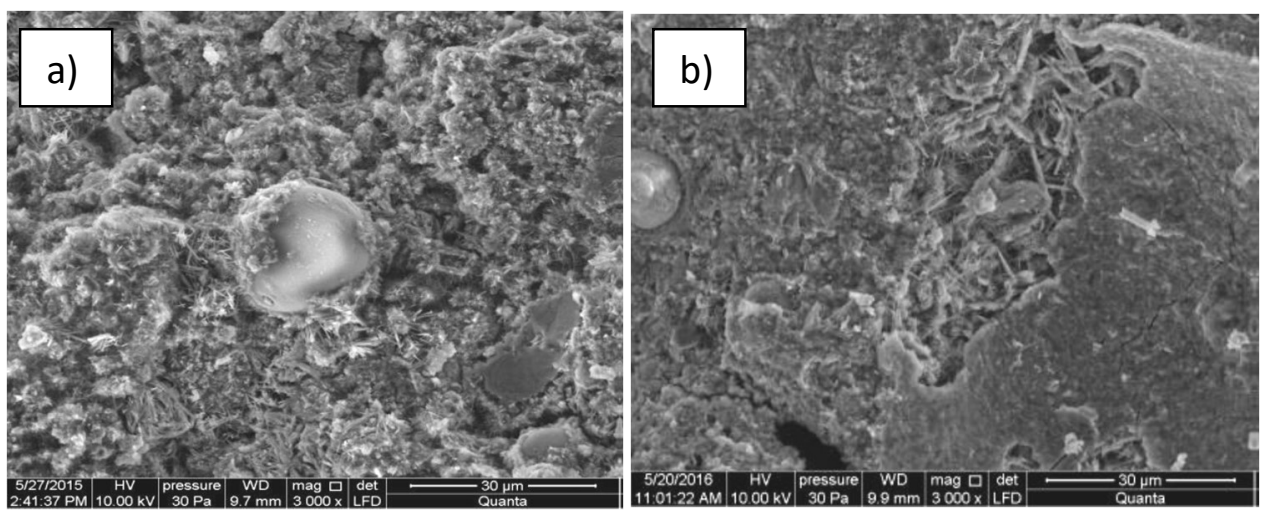

Fig. 6. Microstructure of non-air-entrained mortar with fly ash cement immersed 40 months in sodium sulphate solution. 


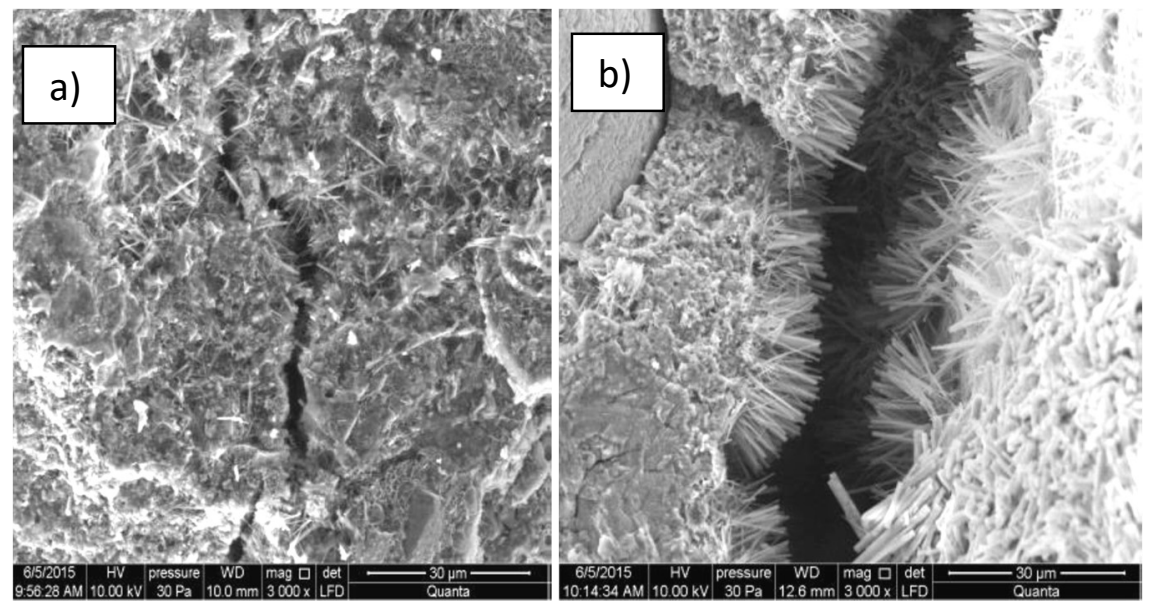

Fig. 7. Microstructure of non-air-entrained fly ash cement mortar specimens after 40 freezing and thawing cycles and 20 months sulphate attack; a), b) micro-cracks in this specimens containing ettringite crystals
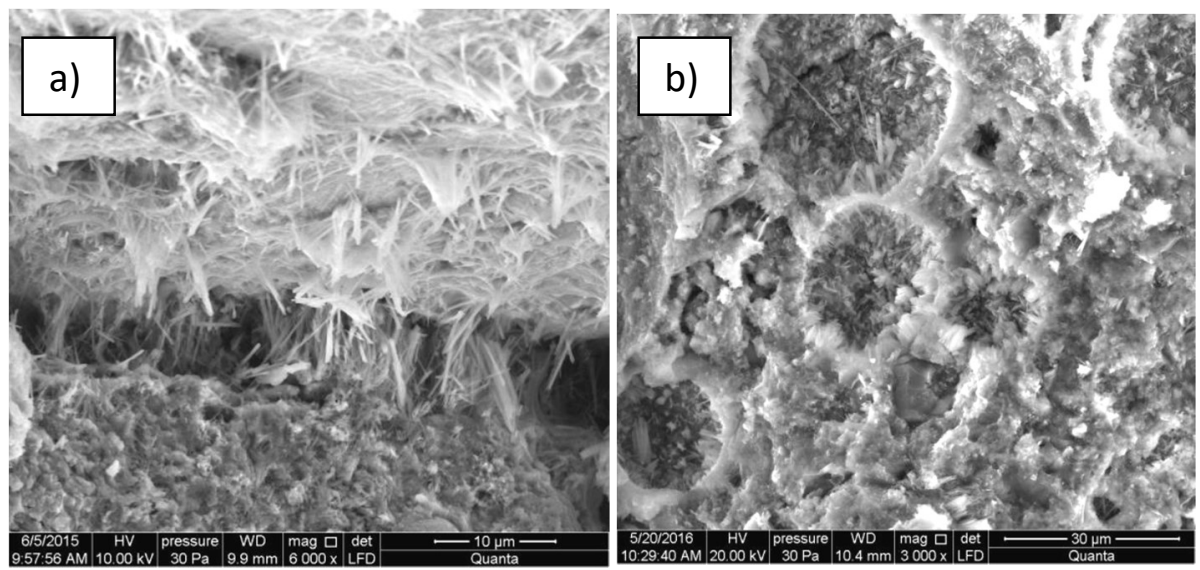

Fig. 8. Microstructure of air-entrained fly ash cement mortar specimens after 40 freezing and thawing cycles and 20 sulphate attack; a) ettringite crystals in micro-cracks; b) airvoid with fine ettringite crystals

\section{Discussion and conclusions}

The best sulphate resistance evaluated in experimental studies was found in mortars with fly ash. Prior freezing/thawing did not reduce their sulphate resistance. The performance of nonair entrained and air-entrained OPC mortars deteriorated considerably in combined destruction conditions. The precipitation of ettringite in very small pores restraining the growth of the crystals will cause mechanical pressure on the pore walls and the expansion of the paste microstructure, whereas the free, unrestrained growth of large ettringite crystals in large pores will not be the cause of expansion in the hardened cement paste. Scherer [20] shows that the crystallization pressure is inversely proportional to the size of pores in which the crystal grows. Thus, the crystals of ettringite growing in small pores of the order of tens of nanometres are probably the most significant factor in generating internal stresses leading to paste expansion during the attack. 
Use the air-entrained mortars with fly ash was considered optimal for maintaining durability under combined freeze-thaw cycles and sulphate attack. The necessity of high quality air-entrained interferes with the properties of fly ash limiting the effectiveness of most air entraining agents, causing technological difficulties [13]. With the increase of unburnt carbon content in fly ash, the effectiveness of chemical admixtures is considerably reduced [21], which significantly limits the concrete's resistance to the addition of fly ash to freezing [22]. Higher doses of air entraining agents or preparations specially dedicated to specific technologies are required [14].

As it should be expected, both air-entrained and non-air-entrained mortars with fly ash presented a very good resistance to sulphate attack. As should also be expected the non-airentrained mortars of fly ash cement are not resistant to cyclic freezing and thawing. Therefore, according to the requirements given in the literature air-entraining of fly ash cement mortars is recommended in order to increase their resistance to sulphate attack, after freezing and thawing cycles.

The freeze-thaw cycles induced elongation of non-air-entrained mortars with fly ash cement but did not caused the acceleration of sulphate attack.

In air-entrained mortars, ettringite is formed mainly in air voids. Large air voids are assuring the free place for ettringite crystallization. And it is the reason of the resistance to sulphate corrosion improvement.

\section{References}

1. J. Skalny, J. Marchand, I. Odler, Sulfate Attack on Concrete, (Spon Press, New-York 2002)

2. J. Clifton, G. Frohnsdorff, C. Ferraris, in Materials Science of Concrete Special Volume: Sulfate Attack Mechanisms, The American Ceramic Society 337-355 (1999)

3. Ch. Miao, R. Mu, Q. Tian, W. Sun, Cem. Concr. Res. 32 31-34 (2002)

4. P.C. Kreijger, Materials and Structures $17275-283$ (1984)

5. J.J. Valenza II, G.W. Scherer, Cem. Concr. Res. 37 1007-1021 (2007)

6. A. M. Neville Wtaściwości betonu. Wydanie V. (Polski Cement, Kraków 2012)

7. S. Chłądzyński, A. Garbacik, Cementy wieloskładnikowe w budownictwie. (Polski Cement, Kraków 2008)

8. E. Tkaczewska, J. Małolepszy, Cement Wapno Beton 1 26-33 (2009)

9. S.M. Torres, C.J. Lynsdale, R.N. Swamy, J.H. Sharp, Cem.Concr.Res. 36384 (2006)

10. 0.S.B. Al-Amoudi, Constr. Build. Materials 9 (3) 149-158 (1995)

11. W. Kurdowski, Chemia cementu i betonu, (PWN Warszawa 2010)

12. P.K. Mehta, P. Schiessl, M. Raupach, 9th ICCC New Delhi, t. I, 571-659 (1992)

13. M. Glinicki, Instytut Badawczy Dróg i Mostów, zeszyt 66, (Warszawa 2011)

14. Z. Rusin, P. Świercz, Budownictwo Technologie Architektura 1 60-62 (2013)

15. PN-88/B-06250:1988 Beton zwykły

16. PN-B-19707:2003 Cement. Cement specjalny - Skład, wymagania i kryteria zgodności

17. PN-EN 206:2014-04 Beton. Wymagania, właściwości, produkcja i zgodność

18. V. Bilek, P. Mec, L. Zidek, T. Moravec, Cement Wapno Beton $8272-78$ (2015)

19. T. Kulovaná, E. Vejmelková, M. Keppert, P. Rovnaníková, M. Ondráček, Z. Keršner, R. Černý, Cement Wapno Beton 82 11-24 (2015)

20. G.W. Scherer, Cem. Concr. Res. 29 (8) 1347 - 1358 (1999) 
21. Z. Giergiczny, Budownictwo Technologie Architektura 3 44-48 (2007)

22. D.M. Roy, 8th ICCC Rio de Janeiro, t. I 362 (1986) 